\title{
Role of Methyl Prednisolone in Longitudinal Extensive Transverse Myelitis (LETM) in Children
}

\author{
Muhammad Azeem Ashfaq ${ }^{1}$, Iram Javed², \\ Muhammad Arshad ${ }^{3}$, Muhammad Rizwan Yaseen ${ }^{4}$
}

\begin{abstract}
Objective: The role of methyl prednisolone in longitudinal extensive transverse myelitis in children is not completely discovered in developing country like Pakistan. So this is the first study which aimed to evaluate the efficacy of methyl prednisolone in longitudinal extensive transverse myelitis in children.

Methods: This is quasi experimental hospital based descriptive prospective study. The data was collected from 34 children admitted in Paediatric Neurology department through Outpatient/emergency department in Children's Hospital and the Institute of Child Health, Lahore for period of one year from January 2018 to December 2018. The children full filling the inclusion criteria were observed before and after giving injection methyl prednisolone $30 \mathrm{mg} / \mathrm{kg} /$ dose (maximum dose one Gram irrespective of the body weight) once daily for five days in the form of intravenous infusion.

Results: Complete recovery was seen in $41.2 \%$ while $58.8 \%$ showed partial recovery. The correlation of response to treatment (recovery) with gender, area of spinal cord involvement, muscle power and autonomic dysfunction is found at significance level of five percent according to Chi square test.

Conclusion: Early consideration and administration of methyl prednisolone in longitudinally extensive transverse myelitis in children can be beneficial and can help to reduce the morbidity.
\end{abstract}

KEYWORDS: Longitudinal Extensive transverse myelitis, Efficacy, Methyl prednisolone.

doi: https://doi.org/10.12669/pjms.36.3.1232

How to cite this:

Ashfaq MA, Javed I, Arshad M, Yaseen MR. Role of Methyl Prednisolone in Longitudinal Extensive Transverse Myelitis (LETM) in Children. Pak J Med Sci. 2020;36(3):451-455. doi: https://doi.org/10.12669/pjms.36.3.1232

This is an Open Access article distributed under the terms of the Creative Commons Attribution License (http://creativecommons.org/licenses/by/3.0), which permits unrestricted use, distribution, and reproduction in any medium, provided the original work is properly cited.

1. Dr. Muhammad Azeem Ashfaq, MBBS, FCPS.

Senior Registrar, Department of Paediatric Neurology,

The Children's Hospital \& the Institute of Child Health, Lahore, Pakistan.

2. Dr. Iram Javed, MBBS, FCPS.

Assistant Professor, Department of Paediatric Neurology, The Children's Hospital Faisalabad, Pakistan.

3. Dr. Muhammad Arshad, MBBS, FCPS

Associate Professor, Sargodha Medical College, Sargodha, Pakistan.

4. Muhammad Rizwan Yaseen,

Assistant Professor, Department of Economics,

Government College University,

Faisalabad, Pakistan.

Correspondence:

Dr. Muhammad Azeem Ashfaq, MBBS, FCPS.

Senior Registrar, Department of Paediatric Neurology,

The Children's Hospital \& the Institute of Child Health,

Lahore, Pakistan.

E-mail: muhammadazeem.ashfaq@yahoo.com

* Received for Publication

June 15, 2019

* Revision Received:

* Revision Accepted:

\section{INTRODUCTION}

Acute transverse myelitis (ATM) presents with acute onset paraplegia or quadriplegia with sensory and autonomic involvement. ${ }^{1}$ Acute transverse myelitis in children being an inflammatory involvement of spinal cord is a rare immunemediated, demyelinating disorder of central nervous system (CNS). ${ }^{2}$ Its incidence in children is 1.7-2 per million children yearly. ${ }^{3}$

Most of cases are seen in adults while 20\% cases are seen below 18 years of age. Mostly cases are idiopathic. Preceding febrile illnesses and vaccination have been reported. ${ }^{4}$ Depending upon the extent of spinal cord involvement, ATM is categorized into short segment and long segment.

Longitudinally extensive transverse myelitis (LETM) is taken to mean myelitis characterized by inflammatory lesion of spinal cord extending 
over $\geq 3$ contiguous spinal cord segments. ${ }^{5}$ LETM occurs in $66 \%-85 \%$ of paediatric ATM. ${ }^{6}$ It appears as hyper intense $\mathrm{T} 2 \mathrm{~W}$ lesions on magnetic resonance imaging (MRI) of spine. It can be complete or incomplete (partial) dysfunction of the spinal cord. ${ }^{7}$ In acute partial transverse myelitis (APTM), clinical presentation can be mild or asymmetric with involvement of one to two vertebral segments in MRI.

A variety of other acquired inflammatory and demyelinating conditions can be associated with LETM. $^{8}$ Not all LETM are Neuromyelitis Optica Spectrum disorder (NMOSD). It can be rare presentation of Mycobacterium tuberculosis infection as well. Acute partial transverse myelitis and brain MRI abnormalities at initial presentation are significantly predictive of a subsequent diagnosis of multiple sclerosis (MS) in children with ATM. ${ }^{9}$

The role of methyl prednisolone in longitudinal extensive transverse myelitis in children is not completely discovered in developing country like Pakistan. So this is the first study which aims to evaluate the efficacy of methyl prednisolone in longitudinal extensive transverse myelitis. It would give a very useful insight regarding formulation of management protocol of LETM locally as well as internationally.

\section{METHODS}

This is quasi experimental hospital based prospective study and conducted in Department of Paediatric Neurology, Children's Hospital \& Institute of Child Health, Lahore for a period of one year from January 2018 to December 2018 after obtaining approval from the Institutional Review Board (Ref. No.: 30085 dated June 4, 2018). Informed written consent was obtained from parents or guardians. The data was collected by nonprobability consecutive sampling technique of 34 children admitted in the department of Paediatric Neurology through Outpatient/ emergency department.

The children of both gender and age ranging from six months to 18 years presenting with acute onset paraplegia or quadriplegia with definite sensory level with or without autonomic involvement of bladder and cardiorespiratory system along with radiologically confirmed findings consistent with longitudinally extensive transverse myelitis with $\geq 3$ contiguous spinal segments involvement were included. While children having spinal cord involvement secondary to other myelocompressive disorders like Pott's disease, spinal tumors and spinal trauma were excluded. Patients were observed after being scrutinized by TMCWG criteria. ${ }^{10}$ All included patients were subjected to detailed neurological examination, spinal MRI and CSF analysis. Base line Neurological status in terms of motor power, sensory, bladder and bowel disturbance were noted. Additional ancillary investigations were also done in selective patients including serological testing, autoimmune profile like ANA, ENA and aquaporinfour antibodies. Data was recorded on predesigned proforma. Injection methyl prednisolone $30 \mathrm{mg} / \mathrm{kg} /$ dose (maximum dose $1 \mathrm{G}$ irrespective of the body weight) once daily for five days in the form of intravenous infusion was given to all children irrespective of time of presentation. Early administration of methyl prednisolone means that it is given within first week and delayed administration means that it is given after first week of onset of illness. Treatment response is noted at 14 days of treatment in terms of improvement in motor power, sensory or autonomic (bowel, bladder) function. Full recovery means attainment of normal motor power with independent ambulation with minimal or no sensory and sphincter disturbances. While partial recovery means that walking with support with spasticity and some sensory signs and urgency of micturition and constipation. No response means unable to walk, absence of sphincter control and sensory deficit.

Data was analyzed by using SPSS v22. Mean and standard deviation are calculated for quantitative variables like age. Descriptive analysis was done by frequency tables. Frequency and percentage are calculated for qualitative variables like sensory level, autonomic dysfunction, need for mechanical ventilation, findings in MRI spine and CSF analysis. Chi square test is applied to see correlation of different variables with response of treatment.

\section{RESULTS}

Thirty four children were enrolled. There were 20 males (58.8\%) and 14 females (41.2\%). Female to male ratio 1:1.4. The age of the children ranged from one year to 13 years with mean age of admission 6.08 years $( \pm 3.53 \mathrm{SD})$. Youngest patient was one year old. Out of 34 patients, $25(73.5 \%)$ patients had involved lower limbs only and $9(26.47 \%)$ patients had both upper and lower limbs involvement. Among these children, only $1(2.9 \%)$ patient required ventilator. Before treatment with steroid 


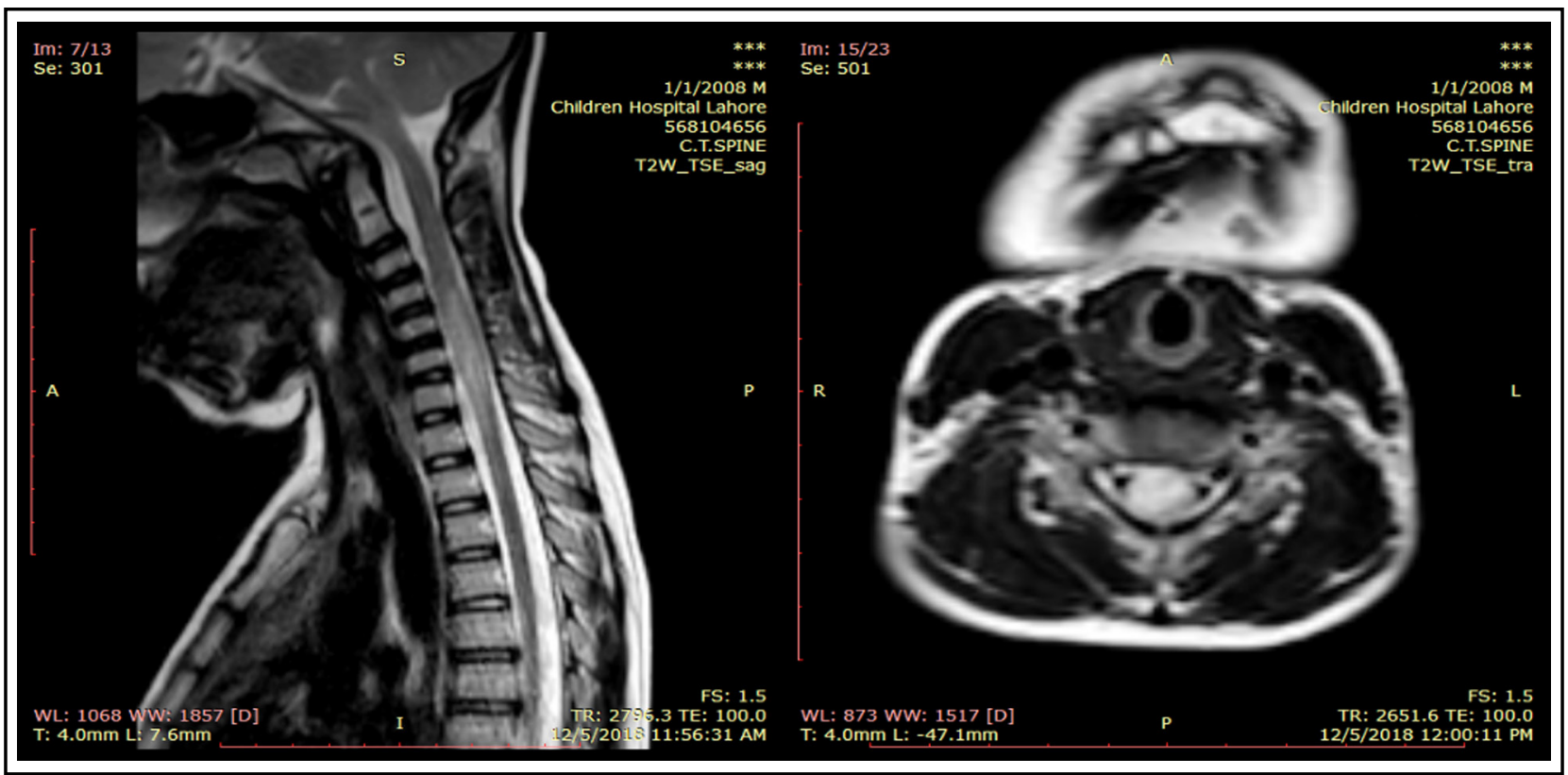

Fig.1: T2 W sagittal and axial MRI through cervical spine. Linear hyperintense area along with swelling within cervical cord (C3-C7) involving upper thoracic cord as well: consistent with long segment Transverse myelitis.

therapy, autonomic dysfunction was found in the form of urinary bladder involvement in 12 patients $(35.3 \%)$ while cardio respiratory dysfunction was found in $7(20.6 \%)$ patient. Six $(17.6 \%)$ children had thoraco-lumbar while 5(14.7\%), 19(55.9\%) and $4(1.8 \%)$ had cervical, cervico-dorsal and whole spine area respectively involved in MRI spine. One patient $1(2.9 \%)$ had cervico-medullary involvement. Majority of patients had cervicodorsal area involved in MRI spine. Sixteen (47\%) children had normal CSF while 18 (53\%) children had both pleocytosis and raised protein values. Thirty one $31(91.2 \%)$ and $3(8.8 \%)$ children had normal and raised CRP respectively. Twenty 24 $(70.6 \%)$ children had history of prior vaccination while $10(29.4 \%)$ had no prior history of febrile illness or vaccination (Table-I).

The correlation of response to treatment (recovery) with gender, treatment, area of spine involved, autonomic dysfunction (bladder and cardiorespiratory) is found significant at significance level of five percent (Table-II).

After five days of treatment completion, power was assessed on $14^{\text {th }}$ day and had been divided into five grades ranging from 0 (lowest) to five (highest) out of total five. According to results, $0 / 5$ and $1 / 5$ grades of power are observed in $5(14.7 \%)$ children. $8(23.5 \%), 7(20.6 \%), 6(17.6 \%)$ and $3(8.8 \%)$ children had $2 / 5,3 / 5,4 / 5$ and $5 / 5$ grades of power respectively after treatment.

\section{DISCUSSION}

Longitudinally extensive Transverse myelitis (LETM) is of course less common but clinically

Table-I: Clinical, lab profile and spinal MRI findings.

\begin{tabular}{llc}
\hline Variable & Categories & Frequency \\
\hline Gender & Male & $20(58.8 \%)$ \\
& Female & $14(41.2 \%)$ \\
Prior febrile & Yes & $24(71 \%)$ \\
illness & No & $10(29 \%)$ \\
Disability & Involvement of lower & $25(73.5 \%)$ \\
at presentation & limbs only (paraplegia) & \\
& Both lower \& upper & $9(26.47 \%)$ \\
& limbs (quadriplegia) & \\
Ventilator & Yes & $1(2.9 \%)$ \\
required & No & $33(97.1 \%)$ \\
CRP & Normal & $31(91.2 \%)$ \\
& Raised & $3(8.8 \%)$ \\
MRI spine & Cervical & $5(14.7 \%)$ \\
& Cervico-dorsal & $19(55.9 \%)$ \\
& Thoraco-lumbar & $6(17.6 \%)$ \\
& Whole spine & $4(1.8 \%)$ \\
MRI brain & Normal & $20(58.8 \%)$ \\
& Abnormal & $3(8.8 \%)$ \\
& NA (not available) & $11(32.35 \%)$ \\
CSF & Normal & $16(47 \%)$ \\
& Raised Protein & $18(53 \%)$ \\
NMO & Yes & $6(17.6 \%)$ \\
antibodies & No & $12(35.29 \%)$ \\
& NA (not available) & $16(47 \%)$ \\
\hline & &
\end{tabular}


Table-II: Correlation between response to treatment and other variables.

\begin{tabular}{|c|c|c|c|c|}
\hline & \multirow{2}{*}{ Categories } & \multicolumn{3}{|c|}{ Response to treatment (Recovery) } \\
\hline & & $\begin{array}{l}\text { Partial } \\
n=20\end{array}$ & $\begin{array}{c}\text { Complete } \\
n=14\end{array}$ & P-value \\
\hline \multirow{2}{*}{ Gender } & Male & $8(21.1 \%)$ & $12(35.3 \%)$ & \multirow{2}{*}{0.009} \\
\hline & Female & $12(35.3 \%)$ & $2(5.9 \%)$ & \\
\hline \multirow[t]{2}{*}{ Treatment } & $\begin{array}{l}\text { Early administeration of } \\
\text { methyl prednisolone }\end{array}$ & $6(35.3 \%)$ & $12(21.1 \%)$ & \multirow[t]{2}{*}{0.02} \\
\hline & Delayed administeration & $14(21.1 \%)$ & $2(17.6 \%)$ & \\
\hline \multirow{4}{*}{ MRI spine area involved } & Thoracolumbar & $6(17.6 \%)$ & 0 & \multirow{4}{*}{0.013} \\
\hline & Cervical & $3(8.8 \%)$ & $2(5.9 \%)$ & \\
\hline & Cervicodorsal & $7(20.6 \%)$ & $12(35.3 \%)$ & \\
\hline & Whole spine area involved & $4(11.8 \%)$ & 0 & \\
\hline \multirow{2}{*}{ Disability at presentation } & Paraplegia & $14(41.17 \%)$ & $11(32.35 \%)$ & \multirow[b]{2}{*}{0.622} \\
\hline & quadriplegia & $6(17.64 \%)$ & $3(8.8 \%)$ & \\
\hline \multirow{2}{*}{ Bladder dysfunction } & Yes & $4(11.8 \%)$ & $12(35.3 \%)$ & \multirow{2}{*}{0.000} \\
\hline & No & $16(47.1 \%)$ & $2(5.9 \%)$ & \\
\hline \multirow{2}{*}{$\begin{array}{l}\text { Autonomic dysfunction } \\
\text { of heart }\end{array}$} & Yes & $2(5.9 \%)$ & $7(20.6 \%)$ & \multirow{2}{*}{0.001} \\
\hline & No & $9(26.5 \%)$ & 0 & \\
\hline \multirow{2}{*}{$\begin{array}{l}\text { Autonomic dysfunction } \\
\text { breathing }\end{array}$} & Yes & $1(2.9 \%)$ & $6(17.6 \%)$ & \multirow{2}{*}{0.001} \\
\hline & No & $9(26.5 \%)$ & 0 & \\
\hline
\end{tabular}

${ }^{*}$ Recovery is taken as categorical variable having two categories i.e. Partial and complete.

more important as early diagnosis and adequate and optimum treatment may prevent many patient from significant morbidities. ${ }^{11,12}$ LETM as such or as a part of Neuromyelitis Optica Spectrum Disorder (NMOSD) may be triggered by various viral agents besides other infectious causes. ${ }^{13}$ There are no strong controlled trial in children for the most effective treatment of ATM, with one study currently going on by Absoud $\mathrm{M}$ et al in UK. ${ }^{14}$ There are very few studies on LETM from developing countries in our region. ${ }^{15}$

In one study, ${ }^{3}$ the complete recovery, mild deficit and severe deficit was seen in five children $(31.2 \%)$, three children and $6(18.7 \%)$ respectively after treatment with methyl prednisolone, but in our study, a complete recovery was also seen in 14 $(41.2 \%)$ children after treatment. Better outcome was noted in females. In a study conducted in India, Pandey S, et al. concluded that early administration of methyl prednisolone reduces the morbidity in these patients. ${ }^{16}$ Similar observation was made in our study. Delayed administration of methyl prednisolone, significant disability at presentation, and an extensive involvement of spinal cord irrespective of the cause, were associated with severe residual disability. ${ }^{17}$ Hence, the beneficial role of methyl prednisolone is proved in our study contrary to the other study by Kalita and Misra in $2001 .{ }^{18}$

Limitation of the study: It is that it is a single center study over a short period. We did not use expanded disability status scale Score for measurement of disability as used by study. ${ }^{19} \mathrm{NMO}$ antibodies and other serological testing were not performed in all patients due to resource constraints. We did not discuss the etiology of LETM and did not observe long term treatment outcome as it was beyond the scope of our study. We feel that our study has got higher percentage of patients of LETM might be due to the reason that our institute is the biggest referral center across the country. This single center prospective study provides information regarding potential benefit of methyl prednisolone in children of our population.

Despite its limitations, major strength of our study is that it provides an insight to develop treatment protocols in children warranting as first line therapy for early management of this potentially 
devastating entity in resource limited developing countries like Pakistan, as most of studies are available on western population. ${ }^{20,21}$

\section{CONCLUSION}

Early consideration and administration of methyl prednisolone in longitudinally extensive transverse myelitis in children can be beneficial and can help reduce the morbidity.

\section{REFERENCES}

1. Wolf VL, Lupo PJ, Lotze TE. Pediatric acute transverse myelitis overview and differential diagnosis. J Child Neurol. 2012;27(11):1426-1436. doi: $10.1177 / 0883073812452916$

2. Tavasoli A, Tabrizi A. Acute Transverse Myelitis in Children, Literature Review. Iran J Child Neurol. 2018;12(2):7-16.

3. Suthar R, Sankhyan N, Sahu JK, Khandelwal NK, Singhi S, Singhi P. Acute transverse myelitis in childhood: A single centre experience from North India. Eur J Paediatr Neurol 2016;20(3):352-360. doi: 10.1016/j.ejpn.2016.01.013

4. Koul R, Alfutaisi AM, Mani R, Rahim RA, Sankhla DK, Al Azri FM. Longitudinal extensive transverse myelitis (LETM) in children: A twenty-year study from Oman. Neurosci. 2017;22(2):127-130. doi: 10.17712/ nsj.2017.2.20160352

5. West TW. Transverse Myelitis-A review of the presentation, diagnosis, and initial management. Discov Med. 2013;16(88):167-177.

6. Deiva K, Absoud M, Hemingway C, Hernandez $Y$, Hussson B, Maurey H, et al. Acute idiopathic transverse myelitis in children: early predictors of relapse and disability. Neurology. 2015;84(4):341-349. doi: 10.1212/ WNL.0000000000001179

7. Thomas T, Branson HM, Verhey LH, Shroff M, Stephens $\mathrm{D}$, Magalhaes S, et al. The demographic, clinical, and Magnetic Resonance Imaging (MRI) features of transverse myelitis in children. J Child Neurol. 2012;27(1):11-21. doi: 10.1177/0883073811420495

8. Tobin WO, Weinshenker BG, Luchiretti CF. Longitudinally extensive transverse myelitis. Curr Opin Neurol 2014;27(3):279-289. doi:10.1097/WCO.0000000000000093

9. Meyer P, Leboucq N, Molinari N, Roubertie A, Carneiro M, Walther-Louvier U, et al. Partial acute transverse myelitis is a predictor of multiple sclerosis in children. Mult Scler J. 2014;20(11):1485-1493. doi:10.1177/1352458514526943

10. Transverse Myelitis consortium working group. Proposed diagnostic criteria and nosocology of acute transverse myelitis. Neurology. 2002;59(4):499-505. doi:10.1212/ wnl.59.4.499

11. Pandit L. Transverse myelitis spectrum disorders. Neurol Ind J. 2009;57:126-133.
12. Eckstein C, Syc S, Siadha S. Differential diagnosis of longitudinally extensive transverse myelitis in adults. Eur Neurol J. 2011;3:27-29.

13. Sellner J, Hemmer B, Muhlau M. The clinical spectrum and immunobiology of parainfectious neuromyelitisoptica (Devic) syndromes. J Autoimmun. 2010;34(4):371-379. doi: 10.1016/j.jaut.2009.09.013

14. Absoud M, Gadian J, Hellier J. Brex PA, Ciccarelli O, Giovannoni G, et al. Trial of Intravenous Immunoglobulin versus standard therapy for the treatment of Transverse Myelitis in adults and Children. (STRIVE). BMJ Open. $2015 ; 25 \mathrm{e} 008312$.

15. Scott TF, Frohman EM, De Seze J, Gronseth GS, Weinshenker BG, Therapeutics and Technology Assessment Subcommittee of American Academy of Neurology. Evidence-based guideline: clinical evaluation and treatment of transverse myelitis: report of the Therapeutics and Technology Assessment Subcommittee of the American Academy of Neurology. Neurology. 2011;77(24):2128-2134. doi:10.1212/WNL.0b013e31823dc535

16. Pandey S, Garg RK, Malhotra HS. Jain A, Malhotra KP, Kumar $\mathrm{N}$, et al. Etiological spectrum and prognosis in noncompressive acute transverse myelopathies: An experience of 80 patients at a tertiary care facility. Neurol India. 2018;66(1):65-70. doi:10.4103/0028-3886.222877

17. Bevan CJ, Cree BA. Fulminant demyelinating disease of central nervous system. Semin Nerol. 2015;35(6):656-666. doi:10.1055/s-0035-1564682

18. Kalita J, Misra UK. Is methyl Prednisolone useful in acute transverse myelitis? Spinal Cord. 2001;39(9):471-476. doi: 10.1038/sj.sc.3101190

19. Bigi S, Banwell B, AnnYeh E. Outcomes after early Administration of Plasma Exchange in Paediatric Central Nervous System Inflammatory Demyelination. J Child Neurol. 2015;30(7):874-880. doi: $10.1177 / 0883073814545883$

20. Waldman AT, Gorman MP, Rensel MR, Austin TE, Hertz DP, Kuntz NL, et al. Management of pediatric central nervous system demyelinating disorders: consensus of United States neurologist. J Child Nurol. 2011;26:675-682. doi: 10.1177/0883073810395141

21. Phol D, Tenembaum S. Treatment of acute disseminated encephalomyelitis. Curr Treat Options Neurol. 2012;14:264-275. doi: 10.1007/s11940-012-0170-0

\section{Authors' Contribution:}

MAA: Conceived the idea and designed framework, Data collection, responsible for accuracy and integrity of work.

MAA, IJ, MA \& MRY: Did manuscript writing and review.

IJ \& MRY: Did statistical analysis. 